\title{
Author Correction: Magnetic configuration effects on the Wendelstein 7-X stellarator
}

A. Dinklage (D), C. D. Beidler, P. Helander, G. Fuchert, H. Maaßberg, K. Rahbarnia, T. Sunn Pedersen, Y. Turkin, R. C. Wolf(D, A. Alonso, T. Andreeva (D), B. Blackwell, S. Bozhenkov DD, B. Buttenschön, A. Czarnecka, F. Effenberg (iD, Y. Feng, J. Geiger, M. Hirsch, U. Höfel (D), M. Jakubowski, T. Klinger, J. Knauer, G. Kocsis, A. Krämer-Flecken (D, M. Kubkowska, A. Langenberg, H. P. Laqua, N. Marushchenko, A. Mollén (D), U. Neuner, H. Niemann, E. Pasch, N. Pablant (D), L. Rudischhauser (D), H. M. Smith, O. Schmitz, T. Stange, T. Szepesi, G. Weir (D), T. Windisch, G. A. Wurden (D), D. Zhang and and the W7-X Team Correction to: Nature Physics https://doi.org/10.1038/s41567-018-0141-9, published online 21 May 2018.

In the version of this Article originally published, and in the associated Publisher Correction, the members of the W7-X Team were not included. All versions of the Article, and the Publisher Correction, have now been amended to include these team members.

\section{Publisher Correction: Routing the emission of a near-surface light source by a magnetic field}

\author{
F. Spitzer (D), A. N. Poddubny, I. A. Akimov DD, V. F. Sapega, L. Klompmaker, L. E. Kreilkamp, L. V. Litvin, R. Jede, \\ G. Karczewski, M. Wiater, T. Wojtowicz, D. R. Yakovlev and M. Bayer
}

Correction to: Nature Physics https://doi.org/10.1038/s41567-018-0232-7, published online 6 August 2018.

In the version of this Article originally published, the expression for $P_{c}$ was missing a division slash; it should have read $P_{\mathrm{c}}= \pm 2 d_{y} d_{z} /\left(d_{y}^{2}+d_{z}^{2}\right) \approx \pm \frac{2}{3} \Delta_{\mathrm{h}, \mathrm{F}} / \Delta_{1 \mathrm{~h}}$. Also, affiliation 5 was missing 'Institute of Physics'; it should have read 'International Research Centre MagTop, Institute of Physics, Polish Academy of Sciences, Warsaw, Poland'. These issues have now been corrected.

Published online: 4 September 2018

https://doi.org/10.1038/s41567-018-0291-9

\section{Author Correction: Higher-order topology in bismuth}

Frank Schindler, Zhijun Wang DD, Maia G. Vergniory, Ashley M. Cook, Anil Murani, Shamashis Sengupta, Alik Yu. Kasumov, Richard Deblock, Sangjun Jeon, Ilya Drozdov, Hélène Bouchiat, Sophie Guéron, Ali Yazdani ID, B. Andrei Bernevig and Titus Neupert (D)

Correction to: Nature Physics https://doi.org/10.1038/s41567-018-0224-7, published online 30 July 2018.

In the version of this Article originally published, B. Andrei Bernevig was missing the following two additional affiliations: Physics Department, Freie Universitat Berlin, Berlin, Germany, and Max Planck Institute of Microstructure Physics, Halle, Germany. This has been corrected in the online versions of the Article. 